\title{
Transcatheter pulmonary valve replacement using the melody valve for treatment of dysfunctional surgical bioprostheses: A multicenter study
}

\author{
Allison K. Cabalka, MD, ${ }^{\mathrm{a}}$ Jeremy D. Asnes, MD, ${ }^{\mathrm{b}}$ David T. Balzer, MD, ${ }^{\mathrm{c}}$ John P. Cheatham, MD, ${ }^{\mathrm{d}}$ \\ Matthew J. Gillespie, MD, ${ }^{\mathrm{e}}$ Thomas K. Jones, MD, ${ }^{\mathrm{f}}$ Henri Justino, MD, ${ }^{\mathrm{g}}$ Dennis W. Kim, MD, PhD, \\ Te-Hsin Lung, PhD, ${ }^{i}$ Daniel R. Turner, MD, ${ }^{j}$ and Doff B. McElhinney, $\mathrm{MD}^{\mathrm{k}}$
}

\section{ABSTRACT}

Background: Stented bioprosthetic valves (BPVs) are commonly used for surgical pulmonary valve (PV) replacement in postoperative congenital heart disease, but develop structural failure in a time-related fashion. The Melody transcatheter PV (TPV) (Medtronic, Minneapolis, Minn) has been used to treat BPV dysfunction, but there have been few studies in this population.

Methods: We performed a retrospective, multicenter study to evaluate Melody valve function in patients who underwent TPV replacement (TPVR) into a dysfunctional pulmonary BPV.

Results: One hundred patients who underwent TPVR at 10 centers between January 2010 and June 2015 were enrolled. The median patient age was 22 years (range, 5-79 years), and 32 patients were age $<18$ years. The underlying diagnosis was tetralogy of Fallot in 80 patients, and moderate or severe pulmonary regurgitation (PR) was present in $84 \%$. The TPV was implanted into various types of BPVs, with a median size of $23 \mathrm{~mm}$ (range, 19-33 mm). At hospital discharge, PR was mild or less in all but 1 patient, and the mean Doppler right ventricular outflow tract (RVOT) gradient was reduced from a mean of $29.3 \pm 12.0 \mathrm{~mm}$ $\mathrm{Hg}$ to $16.2 \pm 6.9 \mathrm{~mm} \mathrm{Hg}$ (median, $29 \mathrm{~mm} \mathrm{Hg}$ to $16 \mathrm{~mm} \mathrm{Hg} ; P<.001$ ). During follow-up (median, 12.4 months), no patients underwent reintervention on the TPV. Endocarditis was diagnosed in 1 patient who was managed medically without intervention. The mean RVOT gradient at the most recent follow-up was $\leq 35 \mathrm{~mm} \mathrm{Hg}$ in all patients, and was similar to that at early postimplantation. PR was more than mild in only 1 patient. Hemodynamic outcomes did not differ between patients with small BPVs $(\leq 23 \mathrm{~mm})$ and those with large BPVs $(\geq 25 \mathrm{~mm})$.

Conclusions: TPVR restores competence and relieves the obstruction of dysfunctional surgical BPVs, with excellent early results in both small and large BPVs, highlighting the potential for TPVR to extend the life of existing BPVs in adults and children. Collaboration between surgeons and cardiologists is important to determine the optimal lifetime management, combining surgical PV replacement and TPVR in this population. (J Thorac Cardiovasc Surg 2018;155:1712-24)

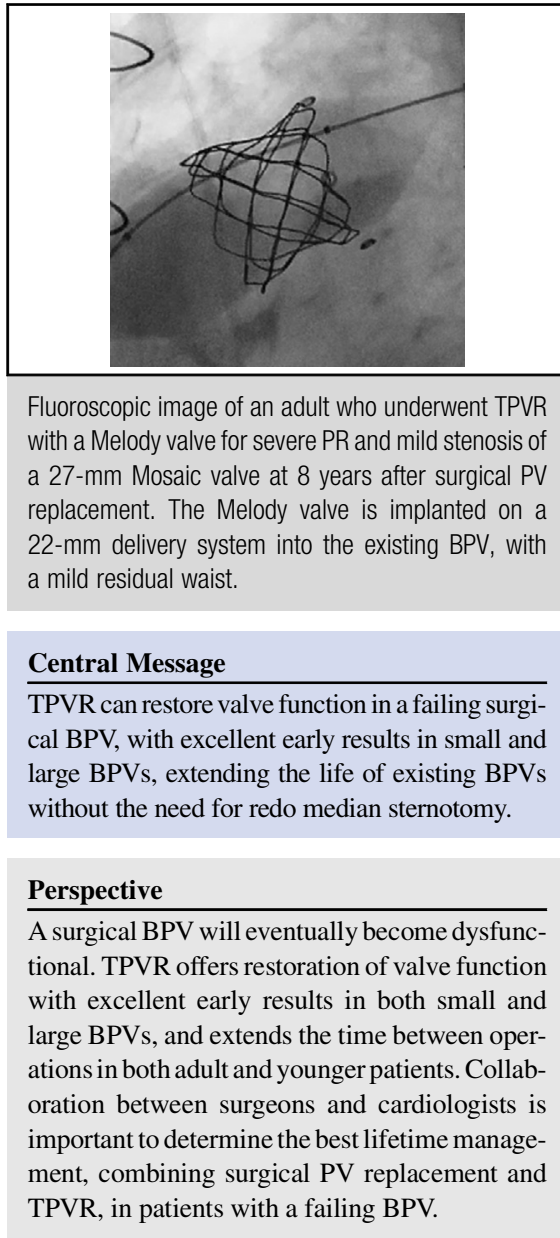

See Editorial Commentary page 1725.

See Editorial page 1710.

\footnotetext{
From the ${ }^{a}$ Division of Pediatric Cardiology, Mayo Clinic College of Medicine, Rochester, Minn; ${ }^{b}$ Division of Pediatric Cardiology, Yale School of Medicine, Yale University, New Haven, Conn; ${ }^{\mathrm{c}}$ Division of Cardiology, Department of Pediatrics, Washington University in St Louis School of Medicine, St Louis, Mo; ${ }^{\mathrm{d}}$ The Heart Center, Nationwide Children's Hospital, Columbus, Ohio; 'Division of Cardiology, Children's Hospital of Philadelphia, Philadelphia, Pa; ${ }^{\mathrm{f}}$ Department of Cardiology, Seattle Children's Hospital, Seattle, Wash; ${ }^{\mathrm{g}}$ Lillie Frank Abercrombie Section of Pediatric Cardiology, Texas Children's Hospital, Baylor College of Medicine, Houston, Tex; ' Division of Pediatric Cardiology, Department of Pediatrics, Children's Healthcare of Atlanta, Emory University, Atlanta, Ga; ${ }^{\mathrm{i} C}$ oronary and Structural Heart Clinical Department, Medtronic, Santa Rosa, Calif; j Division of Pediatric Cardiology, Children's Hospital of Michigan,
}

Detroit, Mich; and ${ }^{\mathrm{k}}$ Department of Cardiothoracic Surgery, Lucille Packard Children's Hospital, Stanford University, Palo Alto, Calif. This study was sponsored and funded by Medtronic.

Read at the 97th Annual Meeting of The American Association for Thoracic Surgery, Boston, Massachusetts, April 29-May 3, 2017.

Received for publication April 25, 2017; revisions received July 21, 2017; accepted for publication Oct 14, 2017; available ahead of print Feb 1, 2018.

Address for reprints: Allison K. Cabalka, MD, Mayo Clinic, Gonda 6, 138-NW, 200 First St SW, Rochester, MN 55905 (E-mail: cabalka.allison@mayo.edu). $0022-5223 / \$ 36.00$

Copyright (C) 2017 by The American Association for Thoracic Surgery https://doi.org/10.1016/j.jtcvs.2017.10.143 


\section{Abbreviations and Acronyms \\ $\mathrm{BPV}=$ bioprosthetic valve \\ CHD = congenital heart disease \\ $\mathrm{PR}=$ pulmonary regurgitation \\ $\mathrm{PV}=$ pulmonary valve \\ RVOT $=$ right ventricular outflow tract \\ $\mathrm{TPV}=$ transcatheter pulmonary valve \\ $\mathrm{TPVR}=$ transcatheter pulmonary valve replacement}

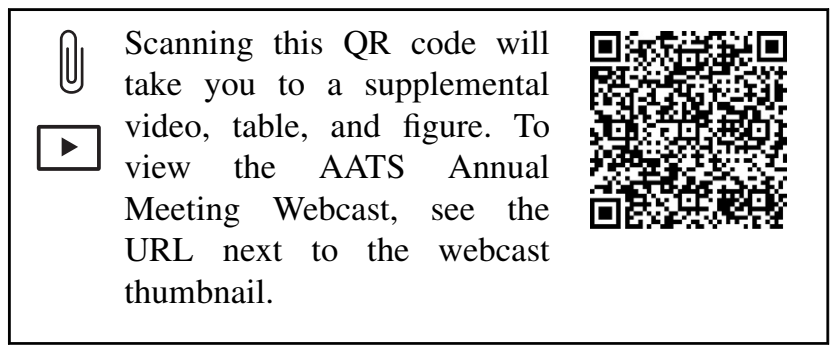

In patients with repaired congenital heart disease (CHD) involving abnormalities of the right ventricular outflow tract (RVOT), surgical pulmonary valve or conduit insertion is frequently necessary to restore valve competence and/or relieve obstruction..$^{1-3}$ In this setting, stented bioprosthetic valves (BPVs) are commonly used. ${ }^{4,5}$ Biological valves inevitably fail, some more rapidly than others. ${ }^{6-10}$ To avoid the need for repeat median sternotomy procedures, less invasive catheter-based interventions to treat pulmonary valve dysfunction have been developed.

In 2010, the Food and Drug Administration approved the Medtronic Melody transcatheter pulmonary valve (TPV) for treatment of moderate or severe pulmonary regurgitation (PR) and/or stenosis, as reflected by a mean RVOT gradient $\geq 35 \mathrm{~mm} \mathrm{Hg}$ in circumferential RVOT conduits. However, in clinical practice, transcatheter pulmonary valve replacement (TPVR) frequently includes off-label placement of the Melody valve to treat a failing BPV. There are few published reports of outcomes in larger series of TPVR in patients with a dysfunctional pulmonary BPV. ${ }^{11-13}$ Therefore, we sought to evaluate the performance of the Melody valve when placed into BPVs in a large multicenter cohort.

\section{METHODS}

\section{Patients and Study Design}

The purpose of this Melody BPV retrospective study was to evaluate the safety and effectiveness of use of the Melody TPV in a dysfunctional BPV in the pulmonary position. Patients who underwent TPVR within a BPV using an 18-, 20-, or 22-mm Ensemble delivery system between January 2010 and June 2015 at 10 centers were included. Institutional Review Board approval was obtained at each site. Medical records were reviewed to assess suitability for inclusion; all patients who met the criteria and provided authorization, when applicable, were consecutively enrolled. Patients were eligible if they had undergone previous implantation of a Melody TPV within a BPV, expanded to $\leq 22 \mathrm{~mm}$ at the time of implantation. Prestenting of the BPV was performed at the implanting physician's discretion, and was most commonly done early in the experience as part of routine practice, to ensure relief of stenosis in the setting of thickened calcified leaflets, and/or to treat supravalvar stenosis with proximal extension of the stent into the existing BPV. Patients who were previously or currently participating in another Medtronic-sponsored Melody TPV study were excluded. As such, this cohort did not include any patients reported in previous publications. ${ }^{11,14,15}$

BPV size was defined as the outer diameter according to the manufacturer's specifications. ${ }^{11}$ For this analysis, data were presented for the overall implanted cohort and also stratified by BPV size. Valve size groups were analyzed both in the entire series and separately in the adult cohort, to avoid bias related to small valves in smaller patients. Three patients with unknown BPV size were excluded from analyses that were dependent on BPV size for stratification.

\section{Procedure and Follow-up}

The TPVR procedure has been described in detail elsewhere. ${ }^{11,14-17}$ Data specific to the catheterization procedure were collected at the time of implantation. Procedural techniques, including angioplasty balloon sizing, prestenting of the RVOT, and postimplantation dilation, were determined by the implanting physician (Video 1). Echocardiograms performed and/or read at the implantation center were used to assess TPV function, with assessment of PR and RVOT mean gradient as described previously. ${ }^{15}$ Procedural success was defined as implantation of the

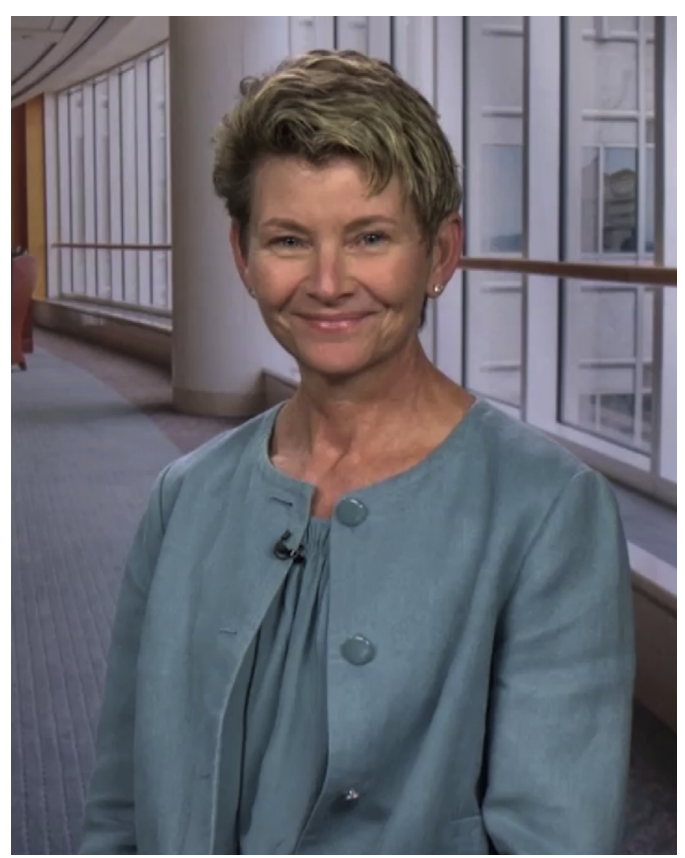

VIDEO 1. A case of Melody valve implantation into an existing 21-mm Hancock bioprosthetic valve in a 16-year-old female with previous tetralogy of Fallot repair. A 20-mm Melody valve was placed into the valve using a 20-mm Ensemble delivery system, and postdilation was performed with an 18-mm Atlas high-pressure balloon. The postimplantation gradient was $13 \mathrm{~mm} \mathrm{Hg}$, with trivial pulmonary regurgitation. Intracardiac echo imaging was used to assess the valve function before and after Melody implantation. Video available at: http://www.jtcvsonline.org/article/ S0022-5223(17)32772-1/fulltext. 
TABLE 1. Demographic data and diagnostic and procedural details

\begin{tabular}{|c|c|c|c|c|}
\hline Variable & $\begin{array}{l}\text { BPV size } \\
\leq 23 \mathrm{~mm} \\
(\mathrm{n}=49)^{*}\end{array}$ & $\begin{array}{l}\text { BPV size } \\
\geq 25 \mathrm{~mm} \\
(\mathrm{n}=\mathbf{4 8})^{*}\end{array}$ & $\begin{array}{l}P \text { value, } \\
\leq 23 \mathrm{~mm} \text { vs } \\
\geq 25 \mathrm{~mm}\end{array}$ & $\begin{array}{l}\text { All patients } \\
(\mathbf{n}=\mathbf{1 0 0})\end{array}$ \\
\hline Age, y, median [range] & $18.0[5.0-47.0]$ & $27.0[10.0-79.0]$ & .01 & $22.0[5.0-79.0]$ \\
\hline Mean \pm SD & $21.0 \pm 10.1$ & $28.0 \pm 13.4$ & - & $24.9 \pm 12.6$ \\
\hline Weight, kg, median [range] & $52.5[15.0-161.2]$ & $71.4[25.7-121.0]$ & .001 & $62.0[15.0-161.2]$ \\
\hline Female sex, \% (n) & $51(25)$ & $38(18)$ & .22 & $46(46)$ \\
\hline $\begin{array}{l}\text { Original diagnosis, } \% \text { (n) } \\
\text { Tetralogy of Fallot } † \\
\text { Pulmonary valve stenosis } \\
\text { Other diagnosis }\end{array}$ & $\begin{array}{c}80(39) \\
8(4) \\
12(6)\end{array}$ & $\begin{array}{c}81(39) \\
13(6) \\
6(3)\end{array}$ & $\begin{array}{r}>.99 \\
.52 \\
.49\end{array}$ & $\begin{array}{c}80(80) \\
11(11) \\
9(9)\end{array}$ \\
\hline $\begin{array}{l}\text { Primary indication for TPVR, \% }(\mathrm{n} / \mathrm{N}) \\
\text { Stenosis } \\
\text { Regurgitation } \\
\text { Mixed stenosis and regurgitation }\end{array}$ & $\begin{array}{l}22(10 / 46) \\
24(11 / 46) \\
54(25 / 46)\end{array}$ & $\begin{array}{l}15(7) \\
29(14) \\
56(27)\end{array}$ & .67 & $\begin{array}{l}18(17 / 97) \\
28(27 / 97) \\
55(53 / 97)\end{array}$ \\
\hline Previous open heart surgeries, median [range] & $2.0[1.0-5.0]$ & $2.0[1.0-5.0]$ & .33 & $2.0[1.0-5.0]$ \\
\hline $\begin{array}{l}\text { Pulmonary regurgitation, } \%(\mathrm{n} / \mathrm{N}) \\
\text { None/trace } \\
\text { Mild } \\
\text { Moderate } \\
\text { Severe }\end{array}$ & $\begin{array}{c}6(3 / 47) \\
15(7 / 47) \\
34(16 / 47) \\
45(21 / 47)\end{array}$ & $\begin{array}{c}5(2 / 44) \\
7(3 / 44) \\
39(17 / 44) \\
50(22 / 44)\end{array}$ & .68 & $\begin{array}{c}5(5 / 94) \\
11(10 / 94) \\
36(34 / 94) \\
48(45 / 94)\end{array}$ \\
\hline $\begin{array}{l}\text { RVOT gradient, mm Hg, median [range] } \\
\quad \text { Mean } \pm \mathrm{SD}(\mathrm{n})\end{array}$ & $\begin{array}{l}32.0[12.0-53.0] \\
32.5 \pm 11.5(39)\end{array}$ & $\begin{array}{c}27.0[3.5-56.0] \\
25.4 \pm 12.0(36)\end{array}$ & $\begin{array}{l}.02 \\
-\end{array}$ & $\begin{array}{c}29.0[3.5-56.0] \\
28.9 \pm 12.1(78)\end{array}$ \\
\hline Previous history of endocarditis, \% (n) & $4(2)$ & $4(2)$ & .81 & $4(4)$ \\
\hline Number of conduits/BPVs before existing BPV, median [range] & $1.0[0-4.0]$ & $1.0[0-3.0]$ & .75 & $1.0[0-4.0]$ \\
\hline Surgical BPV size, mm, median [range] & $23.0[19.0-23.0]$ & $25.0[25.0-33.0]$ & $<.001$ & $23.0[19.0-33.0]$ \\
\hline $\begin{array}{l}\text { BPV size, mm, \% (n) } \\
\quad<21 \\
21 \\
23 \\
25 \\
27 \\
\geq 29\end{array}$ & $\begin{array}{c}16(8) \\
33(16) \\
51(25) \\
0(0) \\
0(0) \\
0(0)\end{array}$ & $\begin{array}{c}0(0) \\
0(0) \\
0(0) \\
56(27) \\
23(11) \\
21(10)\end{array}$ & $<.001$ & $\begin{array}{c}8(8 / 97) \\
17(16 / 97) \\
26(25 / 97) \\
28(27 / 97) \\
11(11 / 97) \\
10(10 / 97)\end{array}$ \\
\hline Sizing or predilation balloon waist, mm, median [range], $\mathrm{n}$ & $18.0[2.0-22.0](37)$ & $20.0[15.0-22.0](31)$ & $<.001$ & $19.0[2.0-22.0](69)$ \\
\hline $\begin{array}{l}\text { Ratio of sizing or predilation balloon waist to BPV size, } \\
\text { median [range], } \mathrm{n}\end{array}$ & $0.85[0.08-1.00](37)$ & $0.76[0.56-0.89](31)$ & $<.001$ & $0.80[0.08-1.00](68)$ \\
\hline $\begin{array}{l}\text { Absolute difference of BPV size minus sizing or predilation } \\
\text { balloon waist, mm, median [range], } \mathrm{n}\end{array}$ & $3.3[0.0-21.0](37)$ & $6.0[3.0-12.0](31)$ & $<.001$ & $4.8[0.0-21.0](68)$ \\
\hline \multicolumn{5}{|l|}{ Concomitant procedures, $\%(\mathrm{n})$} \\
\hline Stent placement, peripheral PA & $10(5)$ & $2(1)$ & .20 & $6(6)$ \\
\hline Balloon angioplasty, peripheral PA & $6(3)$ & $4(2)$ & $>.99$ & $5(5)$ \\
\hline RVOT stent (including prestent within BPV) & $10(5)$ & $19(9)$ & .26 & $14(14)$ \\
\hline Other & $6(3)$ & $15(7)$ & .20 & $10(10)$ \\
\hline $\begin{array}{l}\text { Size of delivery system, } \mathrm{mm}, \%(\mathrm{n} \text { or } \mathrm{n} / \mathrm{N}) \ddagger \\
18 \\
20 \\
22\end{array}$ & $\begin{array}{l}8(4) \\
31(15) \\
61(30)\end{array}$ & $\begin{array}{c}0(0 / 46) \\
2(1 / 46) \\
98(45 / 46)\end{array}$ & $<.001$ & $\begin{array}{c}4(4 / 98) \\
16(16 / 98) \\
80(78 / 98)\end{array}$ \\
\hline Length of hospital stay, d, median [range] & $1.0[0-3]$ & $1.0[0-7]$ & 69 & $1.0[0-7]$ \\
\hline
\end{tabular}

For continuous data, $P$ values are from the Wilcoxon rank-sum test; for categorical data, $P$ values are from the Fisher exact test. $B P V$, Bioprosthetic valve; $S D$, standard deviation; $T P V R$, transcatheter pulmonary valve replacement; $R V O T$, right ventricular outflow tract; $P A$, pulmonary artery. *BPV size not available in 3 patients. $\dagger$ Includes Tetralogy of Fallot with pulmonary atresia. $\ddagger$ Size of delivery system not available for 2 patients. 

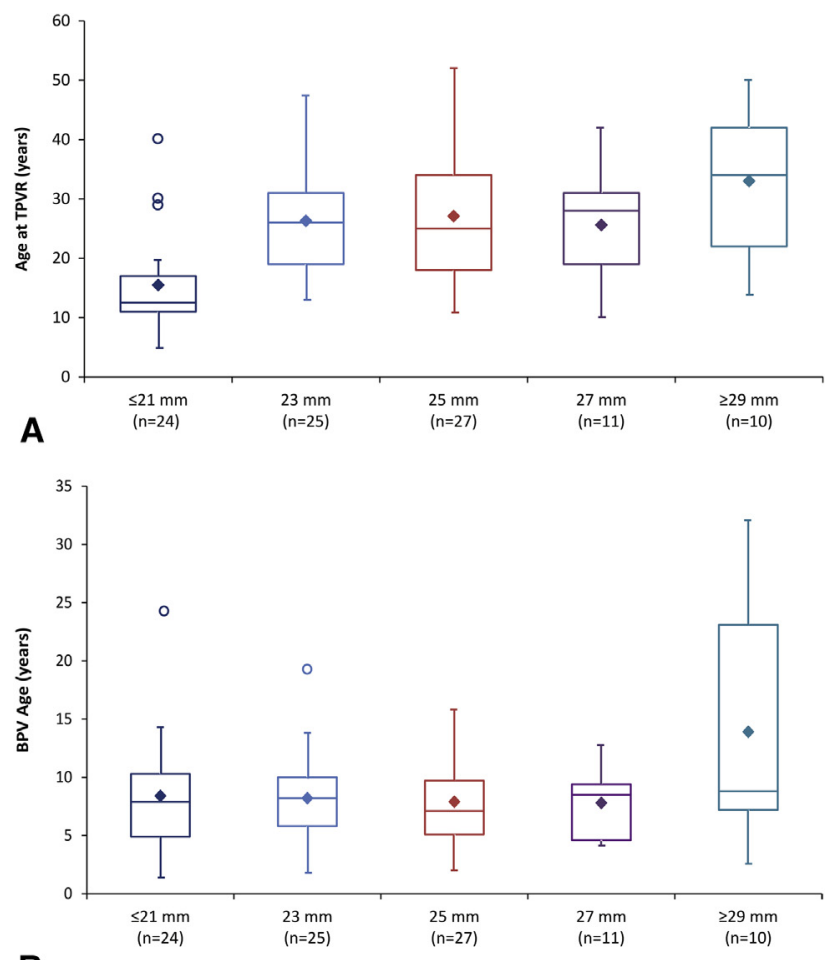

B

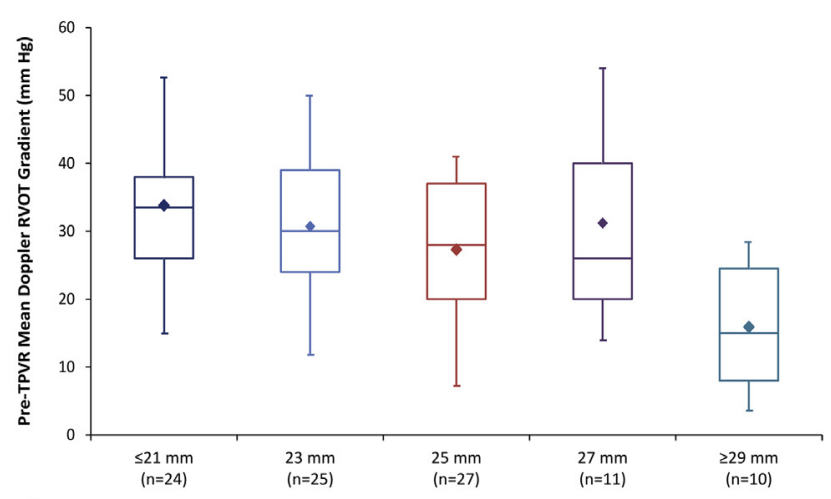

C

FIGURE 1. Age at the time of transcatheter pulmonary valve replacement $(T P V R)(\mathrm{A})$, age of the bioprosthetic valve $(B P V)(\mathrm{B})$, and pre-TPVR mean Doppler right ventricular outflow tract $(R V O T)$ gradient $(\mathrm{C})$, stratified by BPV size group. Age at the time of TPVR was significantly associated with BPV size $(P<.001)$, as was pre-TPVR mean RVOT gradient $(P=.01)$. There was no significant association with age of the BPV $(P=.78)$. The box is centered at the median, with upper and lower bounds of the box representing the 75th and 25th percentiles. The upper and lower ends of the whiskers are at 1.5 interquartile range (IQR) from the 75 th or 25th percentile, respectively, or at the maximum of the observations, whichever is smaller. Circles represent values 1.5 IQR above 75th percentile or 1.5 IQR below 25 th percentile. The $\diamond$ is the mean of the observations. There was 1 outlier, age 79 years, in the $25 \mathrm{~mm}$ BPV group, not shown in the figure.

Melody TPV within the desired location, reduction in catheter-measured RVOT peak-to-peak systolic gradient to $<35 \mathrm{~mm} \mathrm{Hg}$, reduction of PR to mild or less postimplantation, and freedom from TPV explantation at 24 hours. Serious adverse events were defined according to
International Organization for Standardization ISO 14155. Clinical, echocardiographic, and radiographic data were collected at baseline, implantation, discharge, 6 months postdischarge, and annually thereafter, as available. Catheter-based reintervention was defined as balloon dilation or stenting of the TPV, or placement of an additional TPV within the first TPV.

\section{Data Analysis}

The primary outcome measures were safety and effectiveness at 1 year postimplantation. Procedural success, procedure- and device-related serious adverse events, all-cause mortality, freedom from TPV dysfunction, freedom from RVOT reoperation, freedom from catheter reintervention, and hemodynamic performance of the Melody TPV during follow-up were analyzed. TPV dysfunction was defined as the presence of 1 or more of the following: moderate or greater PR, mean Doppler RVOT gradient $>35 \mathrm{~mm} \mathrm{Hg}$, RVOT reoperation for TPV dysfunction or device-related reasons, and/or catheter reintervention on the TPV.

Patients were stratified according to implanted BPV size into 5 groups- $\leq 21 \mathrm{~mm}, 23 \mathrm{~mm}, 25 \mathrm{~mm}, 27 \mathrm{~mm}, \geq 29 \mathrm{~mm}$-which were also collapsed into 2 groups- $\leq 23 \mathrm{~mm}$ and $\geq 25 \mathrm{~mm}$-for selected analyses. The Wilcoxon rank-sum test was used to compare continuous variables, and the Fisher exact test was used to compare categorical variables between the dichotomous groups at baseline and at implantation. The Kruskal-Wallis test was used to compare data among 3 or more BPV size groups. No adjustment was performed for multiple comparisons. For freedom from event analysis, Kaplan-Meier estimates were used to construct the survival curves based on all available follow-up data. Continuous variables are presented as mean \pm standard deviation or median (range). All testing was done using a 2 -sided $\alpha$ level of 0.05 .

\section{RESULTS}

\section{Patients}

At the 10 participating sites, a total of 130 patients underwent Melody TPV implantation within a BPV during the study period, of whom 100 met the study's inclusion criteria and compose our analysis cohort. Demographic data for these patients are are presented in Table 1. The primary indication for intervention was a mixed etiology (stenosis and regurgitation), seen in $55 \%$ of the patients. Four patients had a history of treated pulmonary valve endocarditis either on the BPV or before BPV implantation.

Baseline data are presented according to BPV size ( $\leq 23 \mathrm{~mm}$ or $\geq 25 \mathrm{~mm}$ ) in Table 1 . BPV types included a Carpentier-Edwards valve (Perimount, Magna, other) in 66 patients, a Medtronic valve (Hancock or Mosaic) in 20, a St Jude Epic valve in 10, and other/unknown types in 4. Although the Doppler mean RVOT gradient before TPVR was higher in the $\leq 23 \mathrm{~mm}$ BPV group than in the $\geq 25 \mathrm{~mm}$ group (mean, $32.5 \pm 11.5 \mathrm{~mm} \mathrm{Hg}$ vs $25.4 \pm 12.0 \mathrm{~mm} \mathrm{Hg}$; median, $32.0 \mathrm{~mm} \mathrm{Hg}$ vs $27.0 \mathrm{~mm}$ $\mathrm{Hg} ; P=.02)$, there was no significant difference in the indication for TPVR between the 2 cohorts. Patients with the smallest size BPV tended to be younger than those with larger valves, whereas patients with the largest valves had a longer duration of BPV implantation and a lower mean RVOT gradient (Figure 1). 


\section{Procedure}

Concomitant procedures were performed in a minority of patients (Table 1). When data were available, the median predilation or sizing balloon waist was smaller in the $\leq 23 \mathrm{~mm}$ group compared with the $\geq 25 \mathrm{~mm}$ group $(18.0 \mathrm{~mm}$ vs $20.0 \mathrm{~mm} ; P<.001)$. Fourteen patients underwent BPV prestenting. Most of the Melody valves were implanted using a $22-\mathrm{mm}$ delivery system $(\mathrm{n}=78)$, with a $20-\mathrm{mm}$ system used in 16 patients and an $18-\mathrm{mm}$ system used in only 4 . In 2 patients, the size of the delivery system was not specified. All but 1 of the implants with an 18-mm or 20-mm system were into a 19- to 23-mm BPV.

All patients underwent Melody TPV implantation in the desired location. Procedural success was achieved in $99 \%$ of cases (95 of 96); 1 patient had moderate PR. On discharge echocardiography, only 1 patient had a mean RVOT gradient $>35 \mathrm{~mm} \mathrm{Hg}$; in this patient, the peak-to-peak gradient measured after valve implantation was $14 \mathrm{~mm} \mathrm{Hg}$. Four patients had missing data (1 missing both catheterization and discharge RVOT mean gradient by echocardiography and 3 missing PR by echocardiography), but met all of the other criteria for procedural success.

\section{Safety and Adverse Events}

During a median follow-up of 12.4 months (range, 0-4.4 years) there were no deaths, no explants, and no catheter reinterventions (Figure 2). Two patients experienced 4 procedure-related adverse events; 1 with vascular access site bleeding requiring transfusion, complicated by femoral arteriovenous fistula and pseudoaneurysm requiring surgical repair at 6 weeks postprocedure, and 1 with pulmonary edema postprocedure requiring diuresis. The only devicerelated adverse events noted during follow-up occurred in 1 patient who experienced Streptococcus viridans endocarditis and sepsis at 18 months after TPVR; this patient had no previous history of endocarditis. This was associated with acute valve stenosis and regurgitation that resolved to severe PR with mild to moderate obstruction after 6 weeks of medical therapy. No explantation or replacement of the Melody valve was necessary during follow-up, 4.5 years after the episode.

\section{TPV Function and Hemodynamics}

Freedom from TPV dysfunction at 2 years postprocedure was $96 \%$ (Figure 2). At 1 year, as well as at the most recent follow-up, the mean Doppler RVOT gradient remained $<35 \mathrm{~mm} \mathrm{Hg}$ in $99 \%$ of patients. Furthermore, the mean RVOT gradient remained stable and similar to that at discharge during follow-up (Figure 3, A) $(16.0 \pm 7.7 \mathrm{~mm}$ $\mathrm{Hg}$ vs $15.2 \pm 7.6 \mathrm{~mm} \mathrm{Hg}$; median, $15.0 \mathrm{~mm} \mathrm{Hg}$ vs $14.0 \mathrm{~mm} \mathrm{Hg} ; P=.33$ in patients with evaluable paired data). In the overall cohort, all but 1 patient had mild or less PR at the latest follow-up (Figure 4). There were no differences in postimplantation and follow-up gradients between patients who did and who did not have a prestent placed within the BPV before TPVR.

The mean RVOT gradient at discharge was no different between the $\leq 23 \mathrm{~mm}$ BPV and $\geq 25 \mathrm{~mm}$ BPV groups $(15.9 \pm 7.2 \mathrm{~mm} \mathrm{Hg}$ vs $16.8 \pm 8.2 \mathrm{~mm} \mathrm{Hg}$; median, 15.5 vs $16.6 ; P=.67$ ) (Figure $3, B$ ). One adult patient, with a Melody valve implanted on a 22-mm delivery system into a 25-mm BPV, had a discharge Doppler mean RVOT gradient $>35 \mathrm{~mm} \mathrm{Hg}(41 \mathrm{~mm} \mathrm{Hg})$. At follow-up, where data were available, there were no significant differences in mean RVOT gradient between patients with a pre-TPVR $\leq 23-\mathrm{mm}$ BPV and those with a $\geq 25-\mathrm{mm}$ BPV (Figure 3). Similarly, among patients age $\geq 18$ years, the mean RVOT gradient at 2 years was not significantly different if the TPVR was implanted into a small BPV or a large BPV $(13.7 \pm 7.6 \mathrm{~mm} \mathrm{Hg}$ vs $12.4 \pm 6.2 \mathrm{~mm} \mathrm{Hg}$; median, $12.0 \mathrm{~mm} \mathrm{Hg}$ vs $12.5 \mathrm{~mm} \mathrm{Hg}$; $P=.97$ ) (Figure $3, C$ ). There were 4 patients with a mean RVOT gradient of 25 to $30 \mathrm{~mm} \mathrm{Hg}$ at follow-up: an 11-year-old who underwent TPVR into a 19-mm BPV (mean gradient, $27 \mathrm{~mm} \mathrm{Hg}$ at 1 year), an 18-year-old with a 21-mm BPV (mean gradient, $30 \mathrm{~mm} \mathrm{Hg}$ at 2 years), a 26-year-old with a $25-\mathrm{mm}$ BPV, as described previously, with a high gradient at discharge and a lower gradient at both 6-month and 1-year follow-up visits (mean gradient, $26 \mathrm{~mm} \mathrm{Hg}$ ), and a 31-year-old with a 27-mm BPV (mean gradient, $28 \mathrm{~mm} \mathrm{Hg}$ at 2 years).

\section{Endocarditis}

None of the 4 patients with a known history of endocarditis before undergoing TPVR experienced recurrence during follow-up. One patient developed acute $S$ viridans endocarditis with sepsis at 18 months after TPVR.

\section{DISCUSSION \\ Valve-in-Valve TPVR to Treat Surgical BPV Dysfunction}

As the deleterious effects of chronic PR have been documented, ${ }^{18}$ PVR has become increasingly common in patients who have undergone repair of tetralogy of Fallot and similar anomalies, and there appears to be a trend toward valve implantation to reduce or eliminate PR at younger ages. ${ }^{3}$ Patients undergoing surgical PVR with a BPV inevitably experience failure of the prosthetic valve in a time-dependent fashion, and younger patients may experience shorter freedom from valve dysfunction and/or reintervention. ${ }^{1,4,9,10,19-21}$ The morbidity and potential mortality associated with redo median sternotomy are not inconsequential, and patients with complex CHD are particularly vulnerable when restoration of $\mathrm{PV}$ function may necessitate repeated operations. 2,5,22,23 


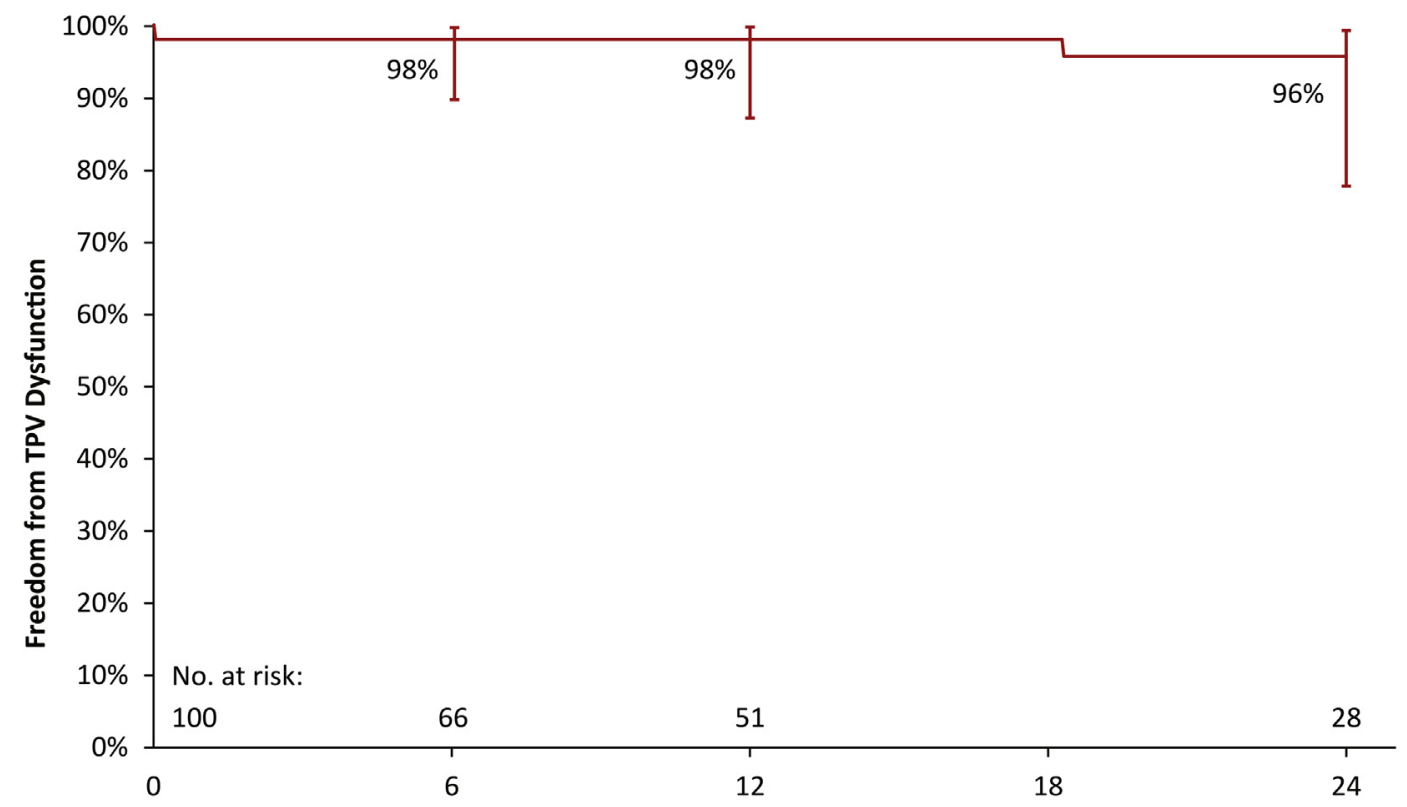

A Months Post-Implant

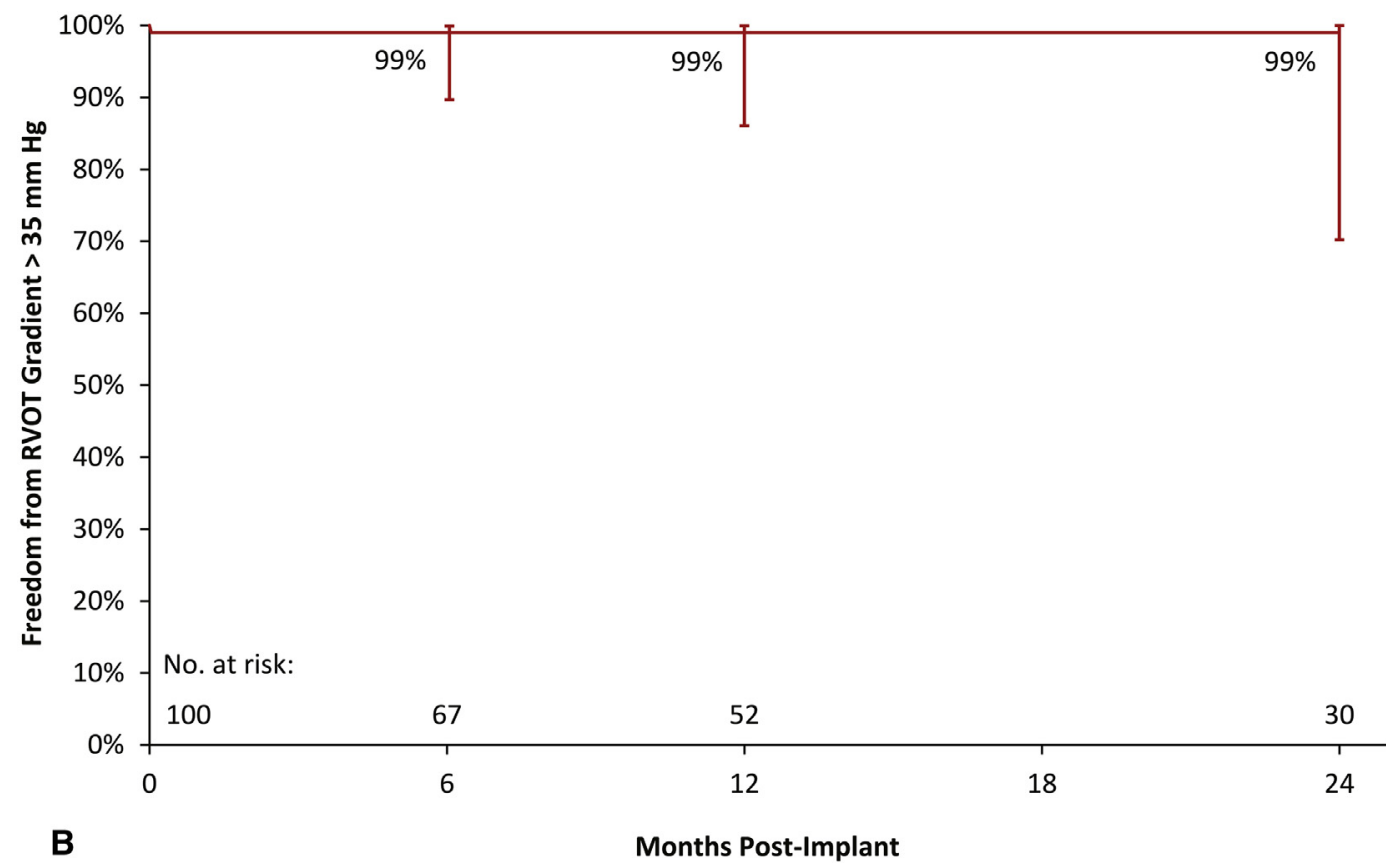

FIGURE 2. Kaplan-Meier curves depicting freedom from transcatheter pulmonary valve dysfunction (A) and freedom from a mean right ventricular outflow tract gradient $>35 \mathrm{~mm} \mathrm{Hg}$ (B). Vertical bars represent $95 \%$ confidence intervals at 6,12 , and 24 months. $T P V$, Transcatheter pulmonary valve; $R V O T$, right ventricular outflow tract.

\section{BPV Size}

Unlike homografts or other RVOT conduits, stented BPVs have a fixed maximum diameter beyond which they cannot be expanded. Although cases have been reported in which the BPV ring has been fractured with an ultra-high-pressure balloon, ${ }^{24,25}$ in general, the maximum internal diameter after valve-in-valve TPVR within a BPV will be several millimeters smaller than the nominal valve size, which typically reflects the outer diameter. Thus, in patients with a dysfunctional BPV in the pulmonary position, BPV size is a consideration when evaluating whether TPVR is a good option. Although the data on valve-in-valve TPVR within BPVs are limited, several investigators have reported smaller series of patients who underwent implantation of a Melody TPV into an existing $\mathrm{BPV},{ }^{11,13}$ and other studies have included BPVs in 


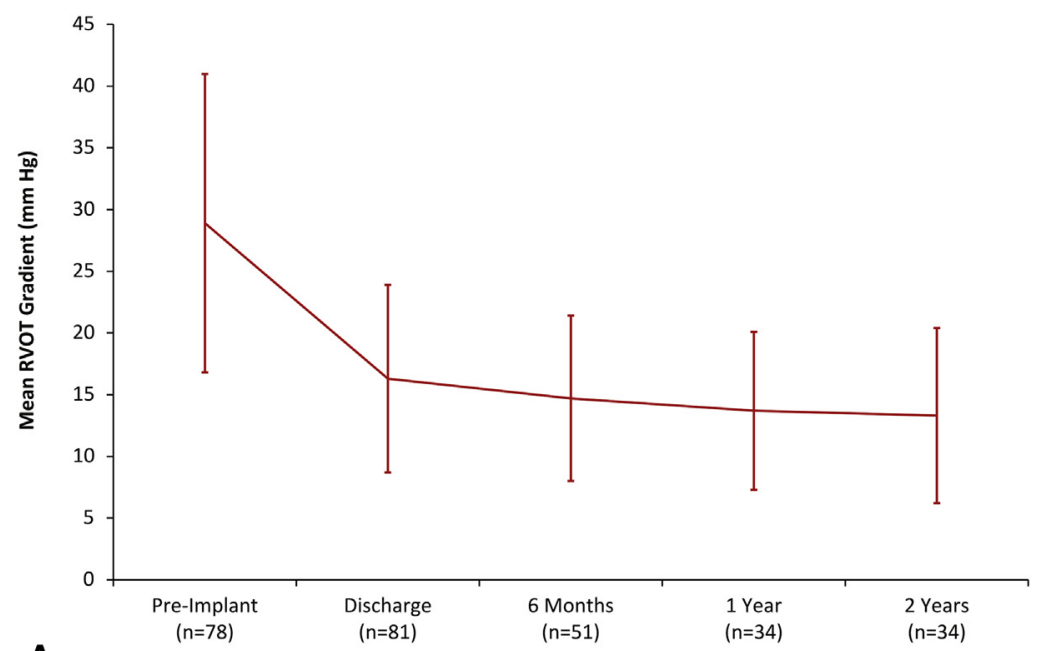

A

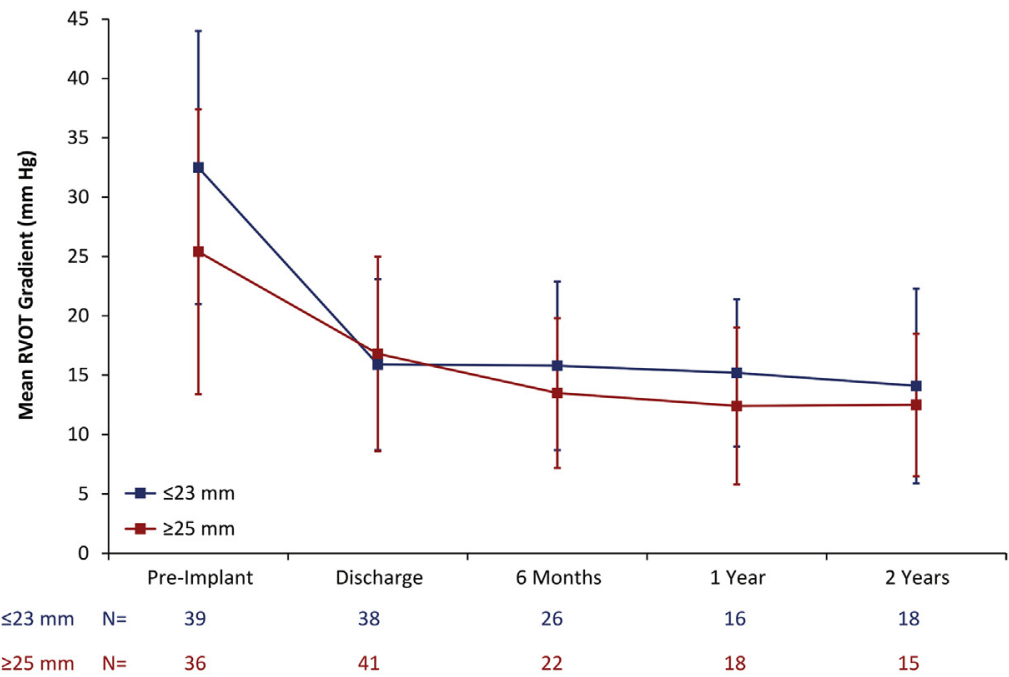

B

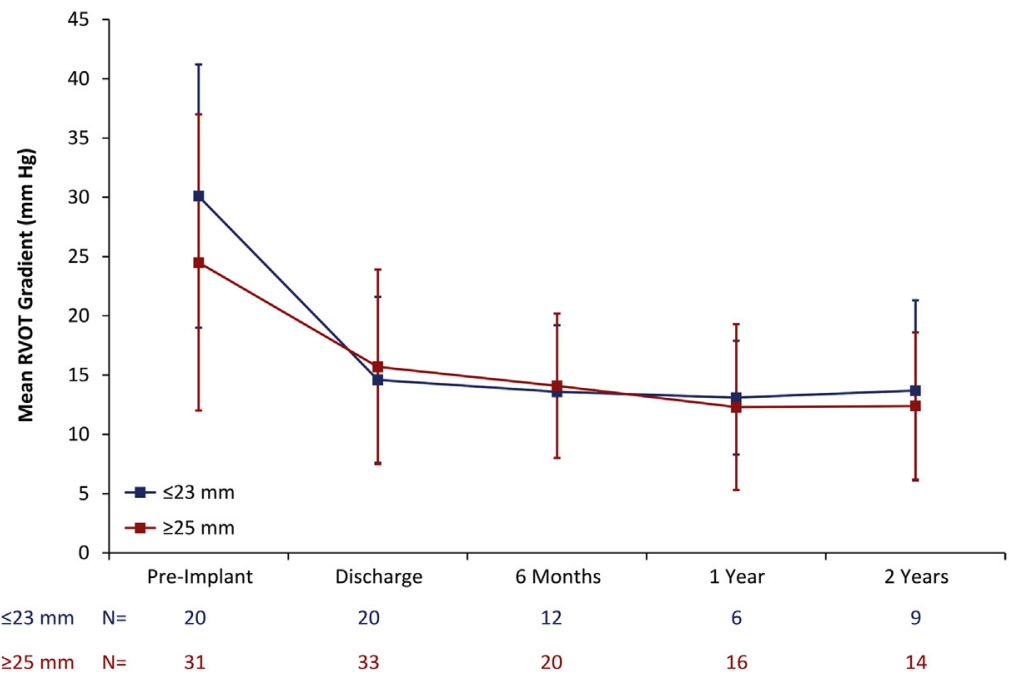

C

FIGURE 3. Doppler mean right ventricular outflow tract gradient over time overall (A), according to bioprosthetic valve (BPV) size (B), and in patients age $\geq 18$ years by BPV size (C). Values are shown as mean \pm standard deviation, represented by error bars. Patients with missing valve size or who did not have an echocardiogram at a given time point are not included. In B and C, $P$ values are nonsignificant between $\leq 23 \mathrm{~mm}$ and $\geq 25 \mathrm{~mm}$ at all follow-up time points. RVOT, Right ventricular outflow tract. 


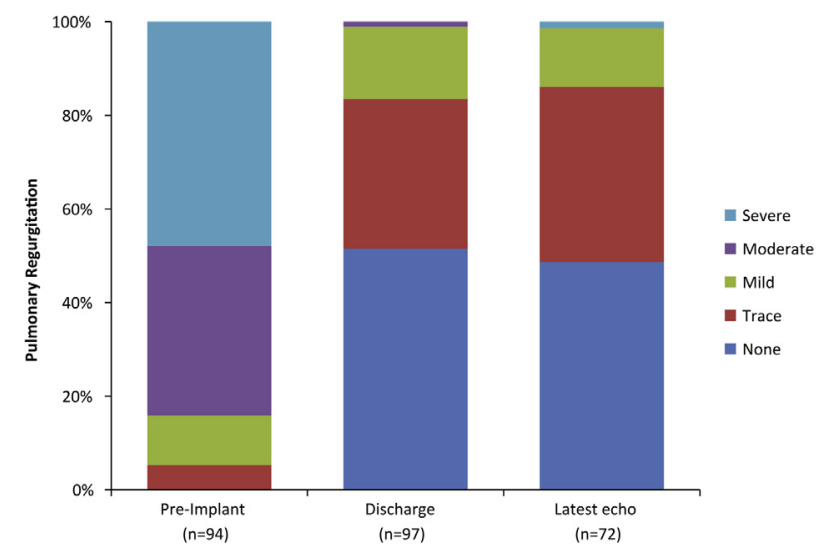

FIGURE 4. Severity of pulmonary regurgitation before implantation, at discharge, and on the most recent echocardiogram (median follow-up duration from implantation to the last available echocardiogram for 72 of the 100 patients with evaluable echocardiographic data, 1.6 years; range, $0.2-4.4$ years).

addition to conduits. ${ }^{12,14-17}$ In 2 recent studies, the investigators directly addressed the question of the optimal size of BPV for subsequent TPVR with a Melody valve, ${ }^{11,13}$ and in 1 study, they postulated that the ideal BPV size is $27 \mathrm{~mm}$, which typically corresponds to a true inner diameter of $\sim 24 \mathrm{~mm} .^{11}$ Although this proposal provides a useful starting point for considering this issue, the findings were preliminary and based on a single center's experience.

In the present study, we analyzed a large series of patients treated with Melody TPVR into an existing BPV at 10 different centers. BPV diameters ranged from 19 to $33 \mathrm{~mm}$. Only 1 patient in our study cohort had more than mild PR at follow-up (after endocarditis), which did not yet prompt intervention. Approximately one-half of our cohort had a TPV implant into an existing BPV of $\leq 23 \mathrm{~mm}$. Although the patients with a BPV $\leq 23 \mathrm{~mm}$ in diameter were younger, weighed less, and had higher preintervention RVOT gradients compared with those with a $\geq 25$-mm BPV, there were no between-group differences in discharge and follow-up mean RVOT gradients over time, even when the analysis was limited to adult patients. In a review of outcomes after surgical PVR, McKenzie and colleagues ${ }^{26}$ identified smaller valve size and age $<13$ years as risk factors for reintervention. Kwak and coworkers ${ }^{27}$ also found that patients age $<20$ years had a higher rate of valve dysfunction than their adult cohort even when a larger size BPV was implanted. Although our follow-up is limited, our patients (either children or adults) with smaller BPVs did not have higher gradients following TPVR, and were not at greater risk of the need for subsequent intervention. Mean RVOT gradients generally remained stable over time. Furthermore, in patients age $\geq 18$ years, hemodynamic values were similar in the $\mathrm{BPV} \leq 23 \mathrm{~mm}$ and $\mathrm{BPV} \geq 25 \mathrm{~mm}$ groups during follow-up, suggesting that surgical re-replacement might not always be necessary in adults with a smaller- diameter BPV. Even if Melody valves implanted into smaller BPVs end up requiring reintervention sooner than those within larger BPVs, the delay in surgical reintervention may reduce the total number of surgical procedures and, consequently, the lifetime risk associated with redo median sternotomy. ${ }^{2,22,23,28,29}$ However, our cohort included only 7 adults with a 19- to 21-mm BPV, and thus whether there is a clear lower BPV size limit for valve-in-valve TPVR is unclear.

With excellent early results and freedom from PR, ongoing follow-up is needed to evaluate longer-term outcomes, particularly with respect to valve function, freedom from reintervention, need for valve re-replacement or explantation, and freedom from endocarditis. This study demonstrates that restoration of pulmonary valve function can be achieved with percutaneous treatment even in smaller, younger patients and in adults with smaller existing BPVs in the pulmonary position.

\section{Integration of TPVR and Surgical Therapy in the Lifetime Management of RVOT Dysfunction}

The findings of this study are encouraging, particularly with respect to TPV function in smaller BPVs. However, acute and mid-term outcomes are only a small part of the calculus that must go into making management decisions in these patients. Most patients with repaired tetralogy of Fallot and related anomalies will require multiple interventions over their lifetime, and it is impossible to predict what technology and alternatives will be available moving forward. For the time being, it is frequently necessary to decide whether to implant a TPV for BPV dysfunction or to place a larger surgical valve in anticipation of future, possibly multiple, TPVR within the surgical valve. Ultimately, the appropriate sequencing of surgical replacement and TPVR will depend on individual circumstances. Certainly, a congenital heart team approach will be needed to determine the best strategy for management of the ever-expanding population of patients with CHD who have undergone surgical BPV placement or replacement. Regardless, TPVR to extend the functional life of an existing BPV will be an important part of therapy, even in patients with a small BPV.

\section{Endocarditis}

Endocarditis has been reported in several patients who underwent TPVR into a BPV. ${ }^{14,30-33}$ The relative risk compared with TPVR within a homograft or other conduit is unknown, but only 1 patient in our series experienced an episode of endocarditis, and none of the 4 patients with a personal history of endocarditis had a recurrence during the study follow-up. The single patient with endocarditis did not undergo explant of the TPV, although severe PR was 
present after the episode was treated medically. Nevertheless, the issue of endocarditis after valve-in-valve TPVR within a pulmonary BPV merits further study.

In a recent study using data from the Society of Thoracic Surgeons registry, $12 \%$ of patients in the adult database undergoing surgical PVR had a previous history of endocarditis. ${ }^{2}$ Although concerns have been raised about infection after TPVR, and a previous history of endocarditis has been documented in a number of cases, ${ }^{32-34}$ previous endocarditis was not associated with adverse outcomes in our present cohort. As increasing numbers of patients with a dysfunctional BPV are considered for TPVR, there is no evidence at this point suggesting that previous endocarditis should be a major factor in the decision making process.

\section{Limitations}

In this retrospective study, implant specifics and clinical follow-up were not available for the entire cohort. There was no echocardiography core lab; site reports were used to determine gradients and valve function. Moreover, the study included only patients who received a Melody valve, and thus does not provide insight into factors that may have been associated with outcomes in patients who were considered for TPVR but did not undergo implantation. We did not evaluate RVOT gradients during exercise, which previous studies have shown to be elevated compared with baseline after TPVR, ${ }^{35}$ and a disproportionate exercise response in patients with different-sized valves is possible.

\section{CONCLUSIONS}

TPVR within a dysfunctional surgical BPV in the pulmonary position can be used to restore competence and relieve obstruction, with excellent early results. Consideration of TPVR is warranted to avoid repeat median sternotomy. Implantation of a TPV into a smaller BPV can be associated with acceptable hemodynamics and valve function, potentially extending the life of an existing BPV to a significant degree. Collaboration between surgeons and cardiologists is important to determine the optimal lifetime management strategy, combining surgical PV replacement and TPVR, in this population.

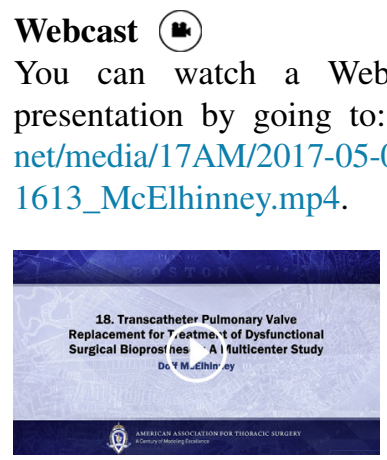

\section{Conflict of Interest Statement}

Dr Asnes is a proctor for Edwards Lifesciences. Dr Balzer is a proctor for Medtronic and Abbott Vascular, and a consultant for Medtronic. Dr Cheatham is a proctor for Medtronic and a consultant for Medtronic, NuMED, Beijing Med-Zenith Medical Scientific, and 480 Biomedical. Dr Gillespie is a consultant for Medtronic. Dr Jones is a proctor and consultant for Medtronic, and receives grant support from Medtronic. Dr Justino is a consultant and proctor for Medtronic, Abbott Vascular, B-Braun Interventional Systems, and Janssen Pharmaceutical. Dr Lung is an employee and shareholder of Medtronic. Dr Turner is a proctor for Abbott Vascular. Dr McElhinney is a proctor and consultant for Medtronic. Drs Cabalka and Kim have nothing to disclose with regard to commercial support.

We thank Jessica Dries-Devlin, PhD, CMPP, for creating all tables and figures, and ensuring technical accuracy of the manuscript, and Kristin Boulware for providing overall study management and a technical review of the manuscript.

\section{References}

1. Batlivala SP, Emani S, Mayer JE, McElhinney DB. Pulmonary valve replacement function in adolescents: a comparison of bioprosthetic valves and homograft conduits. Ann Thorac Surg. 2012;93:2007-16.

2. Khanna AD, Hill KD, Pasquali SK, Wallace AS, Masoudi FA, Jacobs ML, et al. Benchmark outcomes for pulmonary valve replacement using the Society of Thoracic Surgeons databases. Ann Thorac Surg. 2015;100:138-45; discussion 145-6.

3. O'Byrne ML, Glatz AC, Mercer-Rosa L, Gillespie MJ, Dori Y, Goldmuntz E, et al. Trends in pulmonary valve replacement in children and adults with tetralogy of Fallot. Am J Cardiol. 2015;115:118-24.

4. Jang W, Kim YJ, Choi K, Lim HG, Kim WH, Lee JR. Mid-term results of bioprosthetic pulmonary valve replacement in pulmonary regurgitation after tetralogy of Fallot repair. Eur J Cardiothorac Surg. 2012;42:e1-8.

5. Lee C, Lee CH, Kwak JG. Outcomes of redo pulmonary valve replacement for bioprosthetic pulmonary valve failure in 61 patients with congenital heart disease. Eur J Cardiothorac Surg. 2016;50:470-5.

6. Stark J, Bull C, Stajevic M, Jothi M, Elliott M, de Leval M. Fate of subpulmonary homograft conduits: determinants of late homograft failure. J Thorac Cardiovasc Surg. 1998;115:506-14; discussion 514-6.

7. Niemantsverdriet MB, Ottenkamp J, Gauvreau K, Del Nido PJ, Hazenkamp MG, Jenkins KJ. Determinants of right ventricular outflow tract conduit longevity: a multinational analysis. Congenit Heart Dis. 2008;3:176-84.

8. Solomon NA, Pranav SK, Jain KA, Kumar M, Kulkarni CB, Akbari J. In search of a pediatric cardiac surgeon's 'Holy Grail' : the ideal pulmonary conduit. Expert Rev Cardiovasc Ther. 2006;4:861-70.

9. Nomoto R, Sleeper LA, Borisuk MJ, Bergerson L, Pigula FA, Emani S, et al. Outcome and performance of bioprosthetic pulmonary valve replacement in patients with congenital heart disease. J Thorac Cardiovasc Surg. 2016;152: 1333-42.e3.

10. Lee C, Park CS, Lee CH, Kwak JG, Kim SJ, Shim WS, et al. Durability of bioprosthetic valves in the pulmonary position: long-term follow-up of 181 implants in patients with congenital heart disease. J Thorac Cardiovasc Surg. 2011;142:351-8.

11. Gillespie MJ, Rome JJ, Levi DS, Williams RJ, Rhodes JF, Cheatham JP, et al. Melody valve implant within failed bioprosthetic valves in the pulmonary position: a multicenter experience. Circ Cardiovasc Interv. 2012; 5:862-70.

12. Asoh K, Walsh M, Hickey E, Nagiub M, Chaturvedi R, Lee KJ, et al. Percutaneous pulmonary valve implantation within bioprosthetic valves. Eur Heart J. 2010;31:1404-9. 
13. Finch W, Levi DS, Salem M, Hageman A, Aboulhosn J. Transcatheter melody valve placement in large diameter bioprostheses and conduits: what is the optimal "landing zone"? Catheter Cardiovasc Interv. 2015;86:E217-23.

14. Cheatham JP, Hellenbrand WE, Zahn EM, Jones TK, Berman DP, Vincent JA, et al. Clinical and hemodynamic outcomes up to 7 years after transcatheter pulmonary valve replacement in the US Melody valve investigational device exemption trial. Circulation. 2015;131:1960-70.

15. Armstrong AK, Balzer DT, Cabalka AK, Gray RG, Javois AJ, Moore JW, et al. One-year follow-up of the Melody transcatheter pulmonary valve multicenter post-approval study. JACC Cardiovasc Interv. 2014;7: 1254-62.

16. Zahn EM, Hellenbrand WE, Lock JE, McElhinney DB. Implantation of the Melody transcatheter pulmonary valve in patients with a dysfunctional right ventricular outflow tract conduit: early results from the U.S. clinical trial. J Am Coll Cardiol. 2009;54:1722-9.

17. McElhinney DB, Hellenbrand WE, Zahn EM, Jones TK, Cheatham JP, Lock JE, et al. Short- and medium-term outcomes after transcatheter pulmonary valve placement in the expanded multicenter US Melody valve trial. Circulation. 2010;122:507-16.

18. Gregg D, Foster E. Pulmonary insufficiency is the nexus of late complications in tetralogy of Fallot. Curr Cardiol Rep. 2007;9:315-22.

19. Zubairi R, Malik S, Jaquiss RD, Imamura M, Gossett J, Morrow WR. Risk factors for prosthesis failure in pulmonary valve replacement. Ann Thorac Surg. 2011; 91:561-5.

20. Chen PC, Sager MS, Zurakowski D, Pigula FA, Baird CW, Mayer JE Jr, et al. Younger age and valve oversizing are predictors of structural valve deterioration after pulmonary valve replacement in patients with tetralogy of Fallot. J Thorac Cardiovasc Surg. 2012;143:352-60.

21. Caldarone CA, McCrindle BW, Van Arsdell GS, Coles JG, Webb G, Freedom RM, et al. Independent factors associated with longevity of prosthetic pulmonary valves and valved conduits. J Thorac Cardiovasc Surg. 2000;120: 1022-30; discussion 1031

22. Holst KA, Dearani JA, Burkhart HM, Connolly HM, Warnes CA, Li Z, et al. Risk factors and early outcomes of multiple reoperations in adults with congenital heart disease. Ann Thorac Surg. 2011;92:122-8; discussion 129-30.

23. Holst KA, Dearani JA, Burkhart HM, Connolly HM, Warnes CA, Li Z, et al. Reoperative multivalve surgery in adult congenital heart disease. Ann Thorac Surg. 2013;95:1383-9.

24. Brown SC, Cools B, Gewillig M. Cracking a tricuspid perimount bioprosthesis to optimize a second transcatheter sapien valve-in-valve placement. Catheter Cardiovasc Interv. 2016;88:456-9.

25. Tanase D, Grohmann J, Schubert S, Uhlemann F, Eicken A, Ewert P. Cracking the ring of Edwards Perimount bioprosthesis with ultrahigh pressure balloons prior to transcatheter valve in valve implantation. Int J Cardiol. 2014;176: 1048-9.

26. McKenzie ED, Khan MS, Dietzman TW, Guzmán-Pruneda FA, Samayoa AX, Liou A, et al. Surgical pulmonary valve replacement: a benchmark for outcomes comparisons. J Thorac Cardiovasc Surg. 2014;148:1450-3.

27. Kwak JG, Lee C, Lee M, Lee CH, Jang SI, Lee SY, et al. Does implantation of larger bioprosthetic pulmonary valves in young patients guarantee durability in adults? Durability analysis of stented bioprosthetic valves in the pulmonary position in patients with tetralogy of Fallot. Eur J Cardiothorac Surg. 2016;49: 1207-12.

28. Park CB, Suri RM, Burkhart HM, Greason KL, Dearani JA, Schaff HV, et al. Identifying patients at particular risk of injury during repeat sternotomy: analysis of 2555 cardiac reoperations. J Thorac Cardiovasc Surg. 2010;140: 1028-35.

29. Jacobs JP, Mavroudis C, Quintessenza JA, Chai PJ, Pasquali SK, Hill KD, et al. Reoperations for pediatric and congenital heart disease: an analysis of the Society of Thoracic Surgeons (STS) congenital heart surgery database. Semin Thorac Cardiovasc Surg Pediatr Card Surg Annu. 2014;17:2-8.

30. Lurz P, Coats L, Khambadkone S, Nordmeyer J, Boudjemline Y, Schievano S, et al. Percutaneous pulmonary valve implantation: impact of evolving technology and learning curve on clinical outcome. Circulation. 2008;117: 1964-72.

31. Patel M, Malekzadeh-Milani S, Ladouceur M, Iserin L, Boudjemline Y. Percutaneous pulmonary valve endocarditis: incidence, prevention and management. Arch Cardiovasc Dis. 2014;107:615-24.

32. McElhinney DB, Benson LN, Eicken A, Kreutzer J, Padera RF, Zahn EM. Infective endocarditis after transcatheter pulmonary valve replacement using the Melody valve: combined results of 3 prospective North American and European studies. Circ Cardiovasc Interv. 2013;6:292-300.

33. Buber J, Bergersen L, Lock JE, Gauvreau K, Esch JJ, Landzberg MJ, et al. Bloodstream infections occurring in patients with percutaneously implanted bioprosthetic pulmonary valve: a single-center experience. Circ Cardiovasc Interv. 2013;6:301-10.

34. McElhinney DB. Reflection and rationalization: making sense of the literature on endocarditis after transcatheter pulmonary valve replacement. Circ Cardiovasc Interv. 2017;10:e004983.

35. Hasan BS, Lunze FI, Chen MH, Brown DW, Boudreau MJ, Rhodes J, et al. Effects of transcatheter pulmonary valve replacement on the hemodynamic and ventricular response to exercise in patients with obstructed right ventricle-to-pulmonary artery conduits. JACC Cardiovasc Interv. 2014;7:530-42.

Key Words: bioprosthetic valve, Melody valve, transcatheter pulmonary valve, pulmonary regurgitation

\section{Discussion}

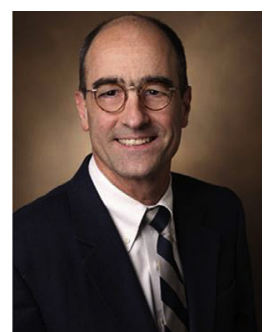

Dr D. Bichell (Nashville, Tenn). In the trade-off between surgeon and cardiologist, and in planning for the future to minimize reintervention, we are often faced with putting the first valve in a dilated RV outflow tract and faced with the question and the luxury of putting whatever size valve we want to put in there. What is the best-sized valve to put in for the future? For a while it was 25 , which is a little suboptimal for some big patients, with a pretty clear consensus that 29 can sometimes be too big, and more recently I personally have moved toward, given the choice of any, putting in a 27. And I just wondered if you could comment on planning of valve size when you can put anyone in for the optimal approach when it falls back into your hands?

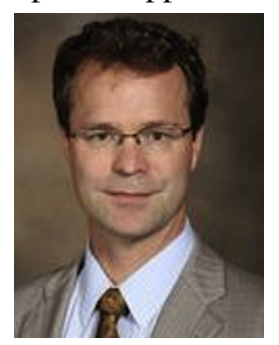

Dr Doff B. McElhinney (Palo Alto, Calif). That's one of the key questions and one of the ways that is important to be able to work together. Obviously, in smaller children, putting in a valve that is too large is often counterproductive. One of the Kaplan-Meier curves I showed in my talk was from a recent large series out of Boston that found a very short freedom from reintervention in patients under 6 years of age at the time of bioprosthetic valve placement. So it is not necessarily doing anybody a favor if you put in a valve that's too large and you get leaflet immobility and dysfunction in the short term.

But assuming we're talking about larger kids and adolescents and adults, I also recommended 25-mm surgical valves when we first started doing these, but clearly you can go bigger and still reliably implant a transcatheter valve. In my experience, you can virtually always get a Melody valve into a $27-\mathrm{mm}$ bioprosthetic valve. I used to 
think that $29-\mathrm{mm}$ valves were too large, or at least liable to be too large, but offhand I can recall that in the last 3 or 4 patients with a $29-\mathrm{mm}$ valve who have come to the cath lab, every single one of them, even with predominant PR and minimal gradient, has been adequate for a Melody valve. My sense is that a $29-\mathrm{mm}$ valve may be actually be a little bit too large for the pulmonary position in many cases, and as a result you tend to get more basal immobility and fusion of the bioprosthetic valve leaflets and it ultimately ends up thickening more, so a Melody valve fits quite well. So, at this point, I'm coming down on the side of a 29-mm valve as ideal, as long as it looks like the right size for that patient.

Dr Bichell. Then a corollary if I might add to that question is about the position of the valve, because from a surgical standpoint, we try to position them distal to the native annulus, pointing in an AP direction, less distorted by the sternum and so forth. Any recommendations about that? If it is placed too proximally and a future stent-based valve is placed and the stent crosses muscle, does muscle crush stent? Are there concerns like that we can plan for as we put these in?

Dr McElhinney. Probably not. In most cases, the entire Melody valve is protected by the bioprosthetic valve, particularly at larger sizes. Rather, when the valve has been placed low or very far out in the outflow tract, particularly in younger children, the occasional difficult problems that I've seen have been obstruction of the outflow tract or pulmonary artery either proximal or distal to the valve, which can be harder to treat.

These valves are quite robust. I've seen a couple of arterial switch patients who ended up having a PVR, with the aorta immediately behind the valve and the sternum immediately anterior, where the frame fractured due to the cyclic compression between the sternum and aorta. That scenario could pose a risk to the Melody valve as well. But, otherwise, I think that the Melody valve is going to be protected within any of these rigid bioprosthetic valves. So whether it's placed lower down in the outflow tract or not, I don't think that's it's an issue as long as the rest of the outflow tract is unobstructed.

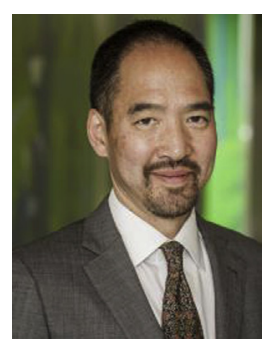

Dr J. Chen (Seattle, Wash). A corollary to the first question. In the horrifying future in which valve in valve and valve in valve-in-valve therapy is being thought of, given your slide and the question about size, each time we are going to be deploying these in there, how much diameter do you think we are going to lose, that is, should we start with 29 , because 3 valves down the road you are going to be down to a 22 or whatever that would be if you sum it up? That's part A. And part B is, is there actually a difference to us noninterventionalists between the Melody and SAPIEN in terms of how much real estate they take up of the diameter?

Dr McElhinney. Two good questions. I think the first one is probably the primary reason that I would move to recommending $29-\mathrm{mm}$ valves, anticipating that you can get an additional catheter valve in there over time.

Now, I don't want to get into this too much, but there are data coming out, mainly in the TAVR world, but we are doing it as well, where you can fracture these bioprosthetic valve rings with ultra-noncompliant balloons; you can crank them up to 20 atmospheres and you can break almost all of them except for the classic Hancocks and several other types. So that may or may not be an option for enlarging bioprosthetic valves moving forward and minimizing the reduction in orifice area that results from valve-in-valve therapy.

Dr Chen. That's not really occurring.

Dr McElhinney. Definitely, people are doing it. I wouldn't bank on it; I wouldn't formulate my plan according to that option. But back to the question of surgical valve size, I would probably go with $29 \mathrm{~mm}$. The thickness of the valve-in-valve, and the diameter reduction, ends up being between $2-1 / 2$ and $3 \mathrm{~mm}$ for the Melody valve, depending on how big it is. The SAPIEN is probably similar. Very limited data have been published on the SAPIEN in this application, so it is very hard to say, but my gestalt is that they are going to be pretty similar.

In the future, who knows what the technology is going to be, so I think we are all speculating, but ideally 2 or 3 valve-in-valve procedures should be enough, if we can get to that point.

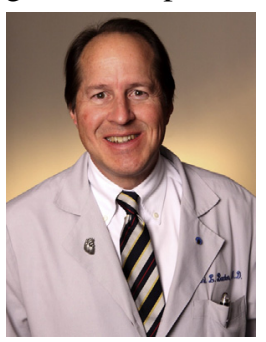

Dr C. Backer (Chicago, Ill). Doff, that was a great presentation, and I congratulate you on coming here. Your information and this kind of interaction are very useful for all of us. Just as Dr Del Nido said in his presidential address, "this is a team sport," and you are the other part of our team.

I have 2 questions. These results are so good, do you think this should change in some way our paradigm for when we put in that first pulmonary valve? Now we have a transcatheter option for a second valve without surgery that appears very effective.

Dr McElhinney. Thanks, Carl. I don't think the data support that yet, but personally I believe that we probably revalve these RVOTs too late as a general practice, and I would like to see, and expect to see, movement toward earlier reintervention.

One of the things that several groups in Belgium and elsewhere are doing in a lot of their straightforward TETs 
is going back to the cath lab when the patient is $8,9,10$ years old, when the RVOT is $20 \mathrm{~mm}$ or so, putting in stents, trying to fix, or limit, the RVOT dilation that occurs over time in anticipation of putting a catheter-based valve in whenever they need it, which may or may not be that late.

The native outflow tract implant is a completely different issue. I' $m$ not talking about that here, but I think people are definitely thinking about how this technology fits into a longer-term management strategy, particularly earlier in life, and I think that is the direction that things will go.

Dr Backer. Certainly in our discussions with the cardiologists, when these patients are presented, we are leaning toward an earlier placement of that first pulmonary valve given that our interventional cardiologists are there to intervene when that first valve starts to fail.

My second question relates to putting transcatheter valves in native outflow tracts. What are your thoughts about that strategy versus having a nice landing zone set up for later transcatheter intervention with almost zero complications? It seems like this is a very nice way to have the second valve; how do you balance those two alternatives?

Dr McElhinney. Certainly the bioprosthetic valve is a great place to put a transcatheter valve; it's protected. It's not foolproof, but it's a very secure and predictable landing zone, it's circumferential, et cetera.

No matter how you slice it, you are going to get into some dilemma about timing when you consider how to use the various technologies over a patient's lifetime. Let's assume that you can put in 2 catheter valves within a bioprosthetic valve before lumen reduction becomes a limiting factor. Thus, if we are performing valve-in-valve therapy in younger patients, at some point we should assume that it will be necessary to replace the valve surgically, and you may get into a situation where you have exhausted transcatheter options with serial valve-in-valve and are facing an older patient who is a less-than-ideal surgical candidate. At the same time, surgical valves have a limited durability; in this series, the median duration of surgical valve implantation was 8.2 years. Although that may be a selected subset, even if bioprosthetic valve longevity is reportedly much longer than that in adults, there are plenty of patients who come in earlier. There is evidence from the STS database that early post-PVR mortality increases with increasing number of prior sternotomies. So what is the trade-off in timing, not only in younger children, but also in good surgical candidates, the 25- to 30-year-old who is quite healthy and would be a good surgical candidate for a valve? Many issues come up here, and I don't think we have the answers, but we should definitely keep our eyes open moving forward to try and understand how best to approach each individual patient.

I think that implants within the native outflow tract are going to fall into 2 categories: balloon-expandable valves within stent frames and self-expanding valve devices designed specifically for the outflow tract. We don't yet know enough about these devices to know how all of this is going to fit together, but this must be developed in conversation among surgeons, interventionalists, and other cardiologists.

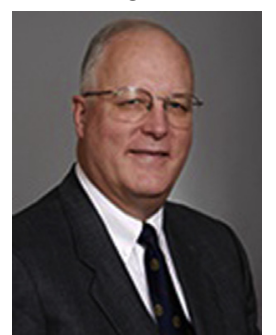

Dr J. Mayer (Boston, Mass). I noticed in the abstract that there was only 1 patient reported with endocarditis on the transcatheter valve, and yet I think increasingly the experience is, particularly with the device made from bovine jugular vein, that endocarditis is a significant problem. We have taken out more than a few of these devices that have been placed either in conduits or within a bioprosthetic valve. I'm interested in your comment on that.

And then a second related question is about the choice of device and whether you think that some of the newer devices, particularly aortic valve transcatheter valves, might offer some advantages, particularly around this issue of endocarditis.

Dr McElhinney. Thanks, John. This was obviously an issue that I was expecting to be questioned about. Honestly, I don't really know the answer. The data in this cohort are what they are. And as we look in a multicenter way we find that endocarditis really varies incredibly. There are some institutions that have put in 200 valves that have zero cases, and some that have put in 40 valves that have 8 cases. It's really quite variable, and we don't know why. I don't want to say that it is institution-related factors that are driving that, but I don't think we understand that story yet, and it is one that we really need to watch closely.

Beyond the bovine jugular vein catheter valves or surgical valves, I think the issue of endocarditis in these patients more broadly is one that we don't understand well. If you look at an article published in Annals of Thoracic Surgery in 2015 reporting on the STS database experience with pulmonary valve replacement, in the adult database, which contained about 6000 patients, $12 \%$ had a prior history of endocarditis. I don't know what that was, I don't know if it was valve-related or not, but I think there is endocarditis out there in this population that we don't fully understand, and we need to work together to try to understand it better.

With respect to the question of whether one valve versus other potential options is going to perform better, either in general or with respect to that question, the jury is definitely still out. If you look at the instructions for use on the SAPIEN valve and its approval for use in RVOT conduits, there was a $5.2 \%$ incidence of endocarditis at 5 years, which is no different than that for the Melody valve. There are very little other published data out there about SAPIEN in the RVOT, so I don't think we know about that yet. It seems 
premature to implicate one particular valve or tissue type until we have better data on all of the options.

On the aortic side, endocarditis, whether it's a SAPIEN, a CoreValve, or other valve, is a real issue and one that is also growing in importance.

I think there is a lot that we need to learn. Endocarditis is an issue of valve function, of morbidity, and in some cases, mortality. It is sometimes a self-limited or easily medically managed problem, sometimes it presents with a fulminant hemodynamic picture and/or sepsis and progresses to death. But that is it not always the picture. If you look at the overall comparative risks and benefits of different therapies, not just endocarditis, but durability more broadly, who knows how that is going to play out? It could play out that a particular valve is just as good or better overall even if there is more endocarditis. There are lots of different pieces to the bigger question of what technology, what therapy is going to be the best in these patients, and I think we owe it to ourselves to take all of that in and make a decision based on the entire picture rather than simply on a single issue.

Dr Mayer. The one editorial comment I would make is that this type of experience argues very strongly for us to continue to try to convert the STS congenital database from a 30-day outcome database to a longitudinal follow-up database. We must have this kind of information to make these kind of did you get through the operation and get out of the hospital into what is really the most effective long-term therapy for the patients. I think it behooves all of us to try to collect as much of that data as we can.

Dr McElhinney. Hear, hear. That would dramatically enhance the value of the STS registry. The IMPACT database, the congenital catheterization database, recently added transcatheter pulmonary valve replacement as a separate module. I chaired that committee, and I essentially insisted that there needed to be a longitudinal component to it, otherwise we weren't going to add it. It will be event-driven and we will see what happens with that, but the most important unanswered questions with many of these therapies are long-term rather than shortterm.

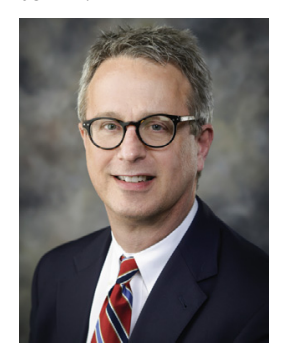

Dr R. Jaquiss (Dallas, Tex). I'd also like to make the editorial comment of how much we appreciate you coming to a surgical meeting. This is a partnership, and there is not enough cross-pollination. So thank you very much. That was a great talk and a great presentation.

Dr McElhinney. Thanks very much. I'll try to be back next year. 


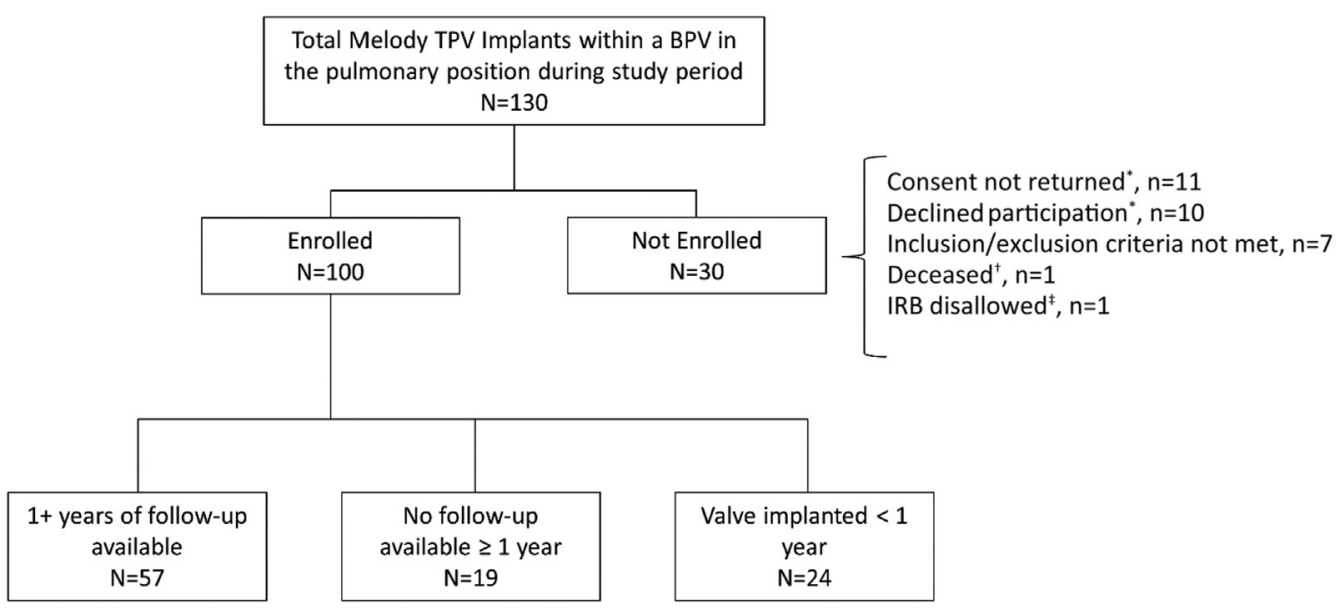

FIGURE E1. BPV retrospective study patient disposition. In total, 130 Melody TPV implantations in the pulmonary position were performed during the study period, and 100 patients were enrolled in the retrospective study. Reasons why 30 patients were not enrolled are shown. In 24 of the 100 enrolled patients, the valve was implanted for $<1$ year; duration of follow-up for the remaining patients is detailed in the flow chart. *The Institutional Review Board (IRB) at 4 sites required informed consent and/or subject notification of data use. †One patient died at a site that required informed consent. Because consent could not be obtained, this patient was not included in the data analysis. $¥$ The IRB did not allow the enrollment of 1 patient based on the date of implantation in relation to humanitarian device exemption discontinuation and premarket approval of the Melody TPV.

TABLE E1. Implanting centers in the BPV retrospective study

\begin{tabular}{ll}
\hline Mayo Clinic & Rochester, Minn \\
\hline Stanford University & Palo Alto, Calif \\
\hline Emory University School of Medicine & Atlanta, Ga \\
\hline Texas Children's Hospital & Houston, Tex \\
\hline Seattle Children's Hospital & Seattle, Wash \\
\hline Nationwide Children's Hospital & Columbus, Ohio \\
\hline Yale-New Haven Hospital & New Haven, Conn \\
Children's Hospital of Philadelphia & Philadelphia, Pa \\
\hline St Louis Children's Hospital & St. Louis, Mo \\
\hline Children's Hospital of Michigan & Detroit, Mich \\
\hline
\end{tabular}

The number of implants ranged from 4 to 17 per center. 